\title{
Aral's potential sources of dust for Moscow region
}

\author{
Karim Shukurov ${ }^{1, *}$, and Lyudmila Shukurova ${ }^{1}$ \\ ${ }^{1}$ A. M. Obukhov Institute of Atmospheric Physics, Russian Academy of Sciences, 119017, Pyzhevsky per., 3, Moscow, Russia
}

\begin{abstract}
Array of 7-day backward trajectories of air particles for Moscow were simulated for days of measurement of volume concentrations of aerosols with particle sizes of 0.1-1.0, 1.0-2.5 and 2.5-5.0 $\mu \mathrm{m}$ at the AERONET site in Moscow in 2001-2018. The CWT (concentration weighted trajectory) method, modified for the atmosphere column, was used to determine the potential sources of aerosols of these three fractions for Moscow region. Potential sources of extreme concentrations of these aerosols in the Moscow atmosphere and the atmospheric circulation pattern favored of their transport to Moscow have been identified.
\end{abstract}

\section{Introduction}

It is widely known that the Aral Sea continues to dry up due to a water deficit of rivers flowing into it [1]. The growing sandy desert on the former bottom of the Aral Sea is a source of fine and coarse mineral and salt aerosols [2], including for the countries of Central Asia. It was established in works [3-5] that aerosol uplift from the underlying surface on the deserted areas of the Aral Sea occurs as a result of both wind and vortex effects, including in convective conditions. Large-scale atmospheric circulation promotes the transport of aerosols from the Aral Sea to long distances [2, 6].

As was established by us earlier [7] from the data of measurements in 2004-2017 at the Zvenigorod Scientific Station (ZSS, $36.8^{\circ}$ E, $55.7^{\circ} \mathrm{N}$ ) of A.M. Obukhov Institute of Atmospheric Physics, the presence of silicates in samples of surface aerosol with particle sizes of 1-2 $\mu \mathrm{m}$ in the Moscow region is associated with the air mass transport from northwestern Kazakhstan and Aral Region. In Moscow $\left(37.2^{\circ}\right.$ E, 55.7 $\left.\mathrm{N}\right)$, the AERONET [8] site has been operating since 2001 [9], so it is interesting to investigate the effect of air transport from northwest Kazakhstan and the Aral Region to the aerosol content in the atmospheric column over the Moscow region.

\section{Data and methods}

In this paper, volume concentrations $\left[\mu \mathrm{m}^{3} / \mu \mathrm{m}^{2}\right]$ of the aerosols in the atmospheric column are used, which are retrieved for a number of aerosol fractions in the range of particle radii of $0.05-15 \mu \mathrm{m}$ by solving the inverse scattering problem [10] using measurements at the AERONET site in Moscow. Level 2.0 data is used only, from which the days of smoke in the Moscow region in August-September 2002 and August 2010 due to forest fires were excluded. Measurements at sites of the
AERONET are conducted during the entire cloudless period of the day several times per hour. In the present study, the aerosol fractions A1, A2 and A3 were used, the particle sizes of which correspond to PM1.0, PM2.5PM1.0 and PM5.0-PM2.5. The concentrations related to one and same hour were averaged.

The trajectory model NOAA HYSPLIT_4 $[11,12]$ and NCEP/NCAR reanalysis [13, 14] were used for calculation of the 7-day backward trajectories of air parcels (elementary air masses) arriving in Moscow during the measurements of the volume concentrations. The duration of the backward trajectories corresponds to the typical lifetime of the aerosol in the troposphere [6, 15]. The volume concentrations refer to the whole column of the atmosphere, and the heights to which the aerosols arrives are not known, it is necessary to calculate trajectories for a number of heights for each measurement of the volume concentration and analyze the trajectories together. We used this approach in [16], where the aerosol potential sources for the south of Siberia are analyzed according to the data of AERONET site in Tomsk $\left(56.5^{\circ} \mathrm{N}, 85.0^{\circ} \mathrm{E}\right)$. As in [16], in this paper the trajectories were calculated for $0.5,1.0,1.5,2.0,3.0$, 4.0 and $5.0 \mathrm{~km}$, i.e. for the lower and middle troposphere. The influence of the layers above $5 \mathrm{~km}$ in this paper is neglected.

Using the obtained array of backward trajectories, the CWT (concentration weighted trajectory) method [17] was used for reconstructing the fields of the average contribution of remote potential sources to the volume concentration of the aerosols in the atmosphere over Moscow for specified fractions. Since, on average, the aerosol concentration decreases with altitude [6], the trajectories arriving in Moscow at different altitudes were taken into account with different weights. In the first approximation, we can assume that the mean aerosol profiles for Moscow are close to the

\footnotetext{
* Corresponding author: karim.shukurov@ifaran.ru
} 
corresponding profiles for Tomsk for the warm and cold seasons of the year, so in this paper the backward trajectories related to different heights are taken with those the same weights as in [16]. The fields $\left(2.5^{\circ} \times 2.5^{\circ}\right.$ cells) were displayed using the Meteo-Info GIS software [18]. The cells to be hit with at least 50 independent backward trajectories are considered as statistically significant only.

\section{Results}

In total, 11600 backward trajectories were modeled, of which $90 \%$ were related to the warm season from April to September. This is due to the fact that there are more cloudless days in the Moscow region and their duration is longer in the warm season than in the cold season. In Fig. 1 shows the logarithm of the probability of air parcels transport into the tropospheric column above Moscow from the atmospheric column with a base $2.5^{\circ} \times$ $2.5^{\circ}$ for the whole array of trajectories. As can be seen from Fig. 1 in the layer $<5 \mathrm{~km}$ above Moscow is dominated by the western transport of air masses.
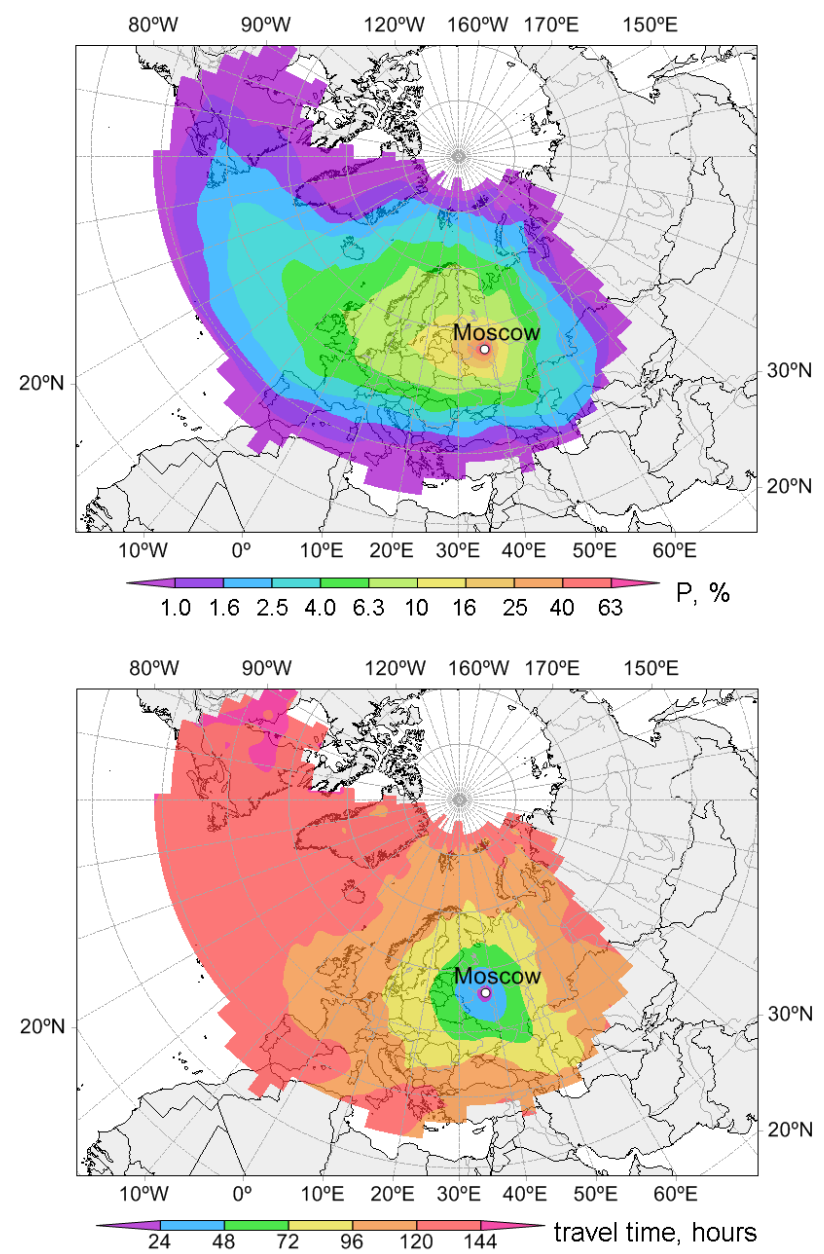

Fig. 1. The transport probability (a) and the average time of air parcel transport to Moscow (b).

Despite the fact that the Aral Sea is 2-2.5 times closer than the North Atlantic, the probability of the transport from cells measuring $2.5^{\circ} \times 2.5^{\circ}$ is the same, $2.5-4 \%$ (Fig. 1a). The mean time for the transport of air parcels in the
0.5-5.0 km layer from the Aral Sea is 3-4 days (Fig. 1b), i.e. less than the average life time ( 7 days) of aerosols in the troposphere $[6,15]$.
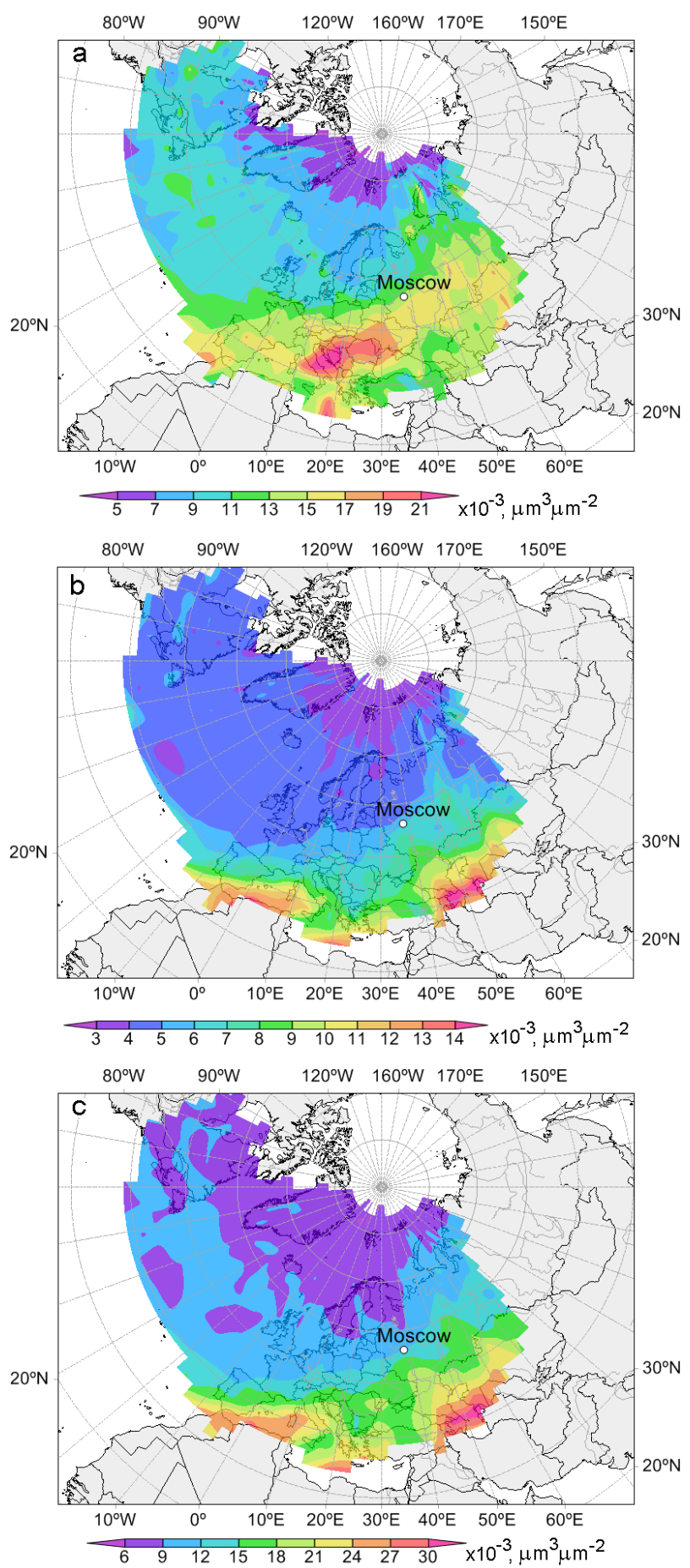

Fig. 2. The average contribution of potential source to the volume concentration of the aerosols in the troposphere over Moscow for the fractions A1 (a), A2 (b) and A3 (c)

The form of the contribution field of remote potential sources to the volume concentration of aerosols over the Moscow region depends on the aerosol fraction. As can be seen from Fig. 2a, the largest contribution to A1 over Moscow is connected to the vast region of southern Europe from Italy to Romania. The maximum average contribution to A2 and A3 is related to the Aral Region, 
the Ustyurt plateau, as well as the Transcaucasia, and North Africa (Fig. 2b and 2c). Transcaucasia, probably, is only a transit region for aerosols transported from the Aral Region, and possibly also from the deserts of the Iranian highland and Syria. The similarity of the potential sources for A2 and A3 may indicate the unified origin of the aerosols of these fractions.
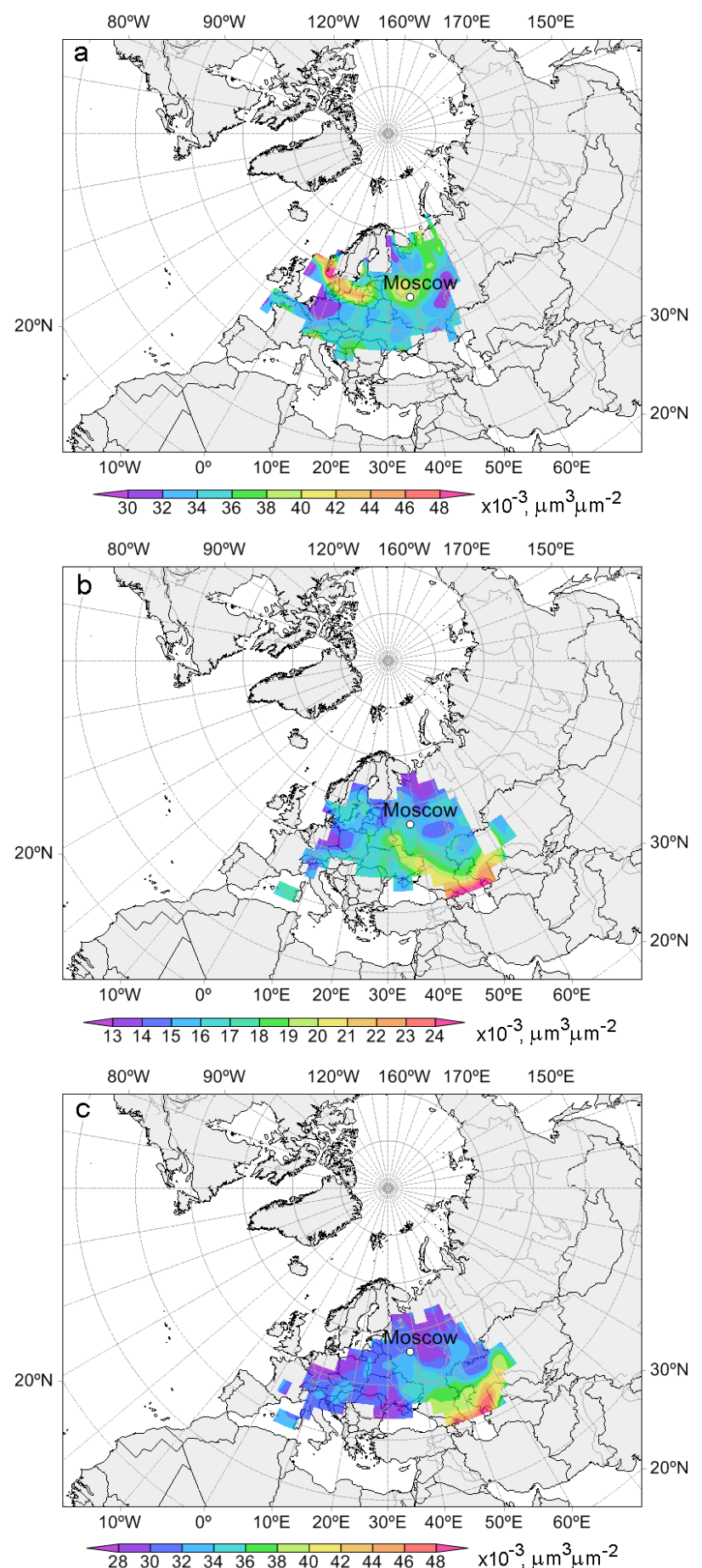

Fig. 3. The average contribution of the remote potential source in the extreme aerosol concentrations of the fractions A1 (a), A2 (b) and A3 (c) in the troposphere above Moscow.

Extreme $(10 \%$ of the highest values of the distribution function) concentrations of fraction $\mathrm{A} 1, \mathrm{~A} 2$ and $\mathrm{A} 3$ in Moscow are in the ranges, respectively, $>23$ $\mu \mathrm{m}^{3} / \mu \mathrm{m}^{2},>10 \mu \mathrm{m}^{3} / \mu \mathrm{m}^{2}$ and $>22.5 \mu \mathrm{m}^{3} / \mu \mathrm{m}^{2}$. Sources of extreme concentrations of A1 are near the south of the Scandinavian Peninsula and the Baltic Sea, as well as near Moscow (Fig. 3a), i.e. it is most likely that extreme A1's are not arid aerosols. Extreme values of A2 and A3 are associated with the transport from the Aral Region and the Caspian Region (Fig. $3 \mathrm{~b}$ and 3c). Fraction A2 is similar in particle size to surface aerosol (1-2 $\mu \mathrm{m})$ from [7]. Since the silicates in the composition of the aerosols from [7] came from the Aral Region [7], it can be assumed that the aerosols of fraction A2 (and possibly A3), coming from the Aral Region, contains many silicates too.
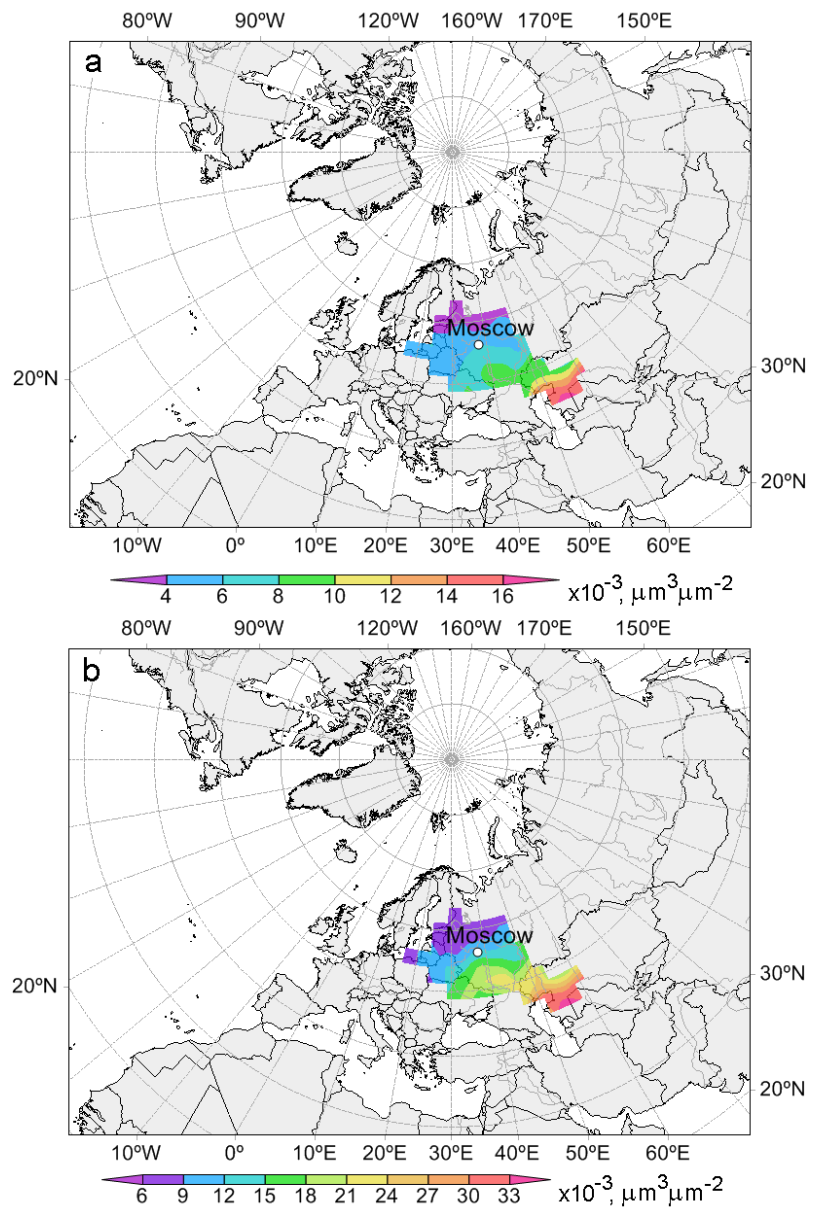

Fig. 4. The average contribution of the mixed layer sources into the aerosol concentration of the fractions A1 (a), A2 (b) and A3 (c) in the troposphere above Moscow.

As can be seen from Fig. 3, North Africa and the Middle East are not sources of extreme concentrations of $\mathrm{A} 2$ and $\mathrm{A} 3$ in Moscow. The high values of A2 and A3 coming from the Aral Region are apparently due to the fact that it is in this region that the air particles moving to Moscow enter the mixed layer (Figs $4 a$ and $4 b$ ), i.e. the layer most susceptible to the influence of the underlying surface $[6,19,20]$.

It was shown in [21] that the transport of silicates from the Aral Region to the near-surface layer in the Moscow region was due to a blocking anticyclone centered over the middle Urals. 


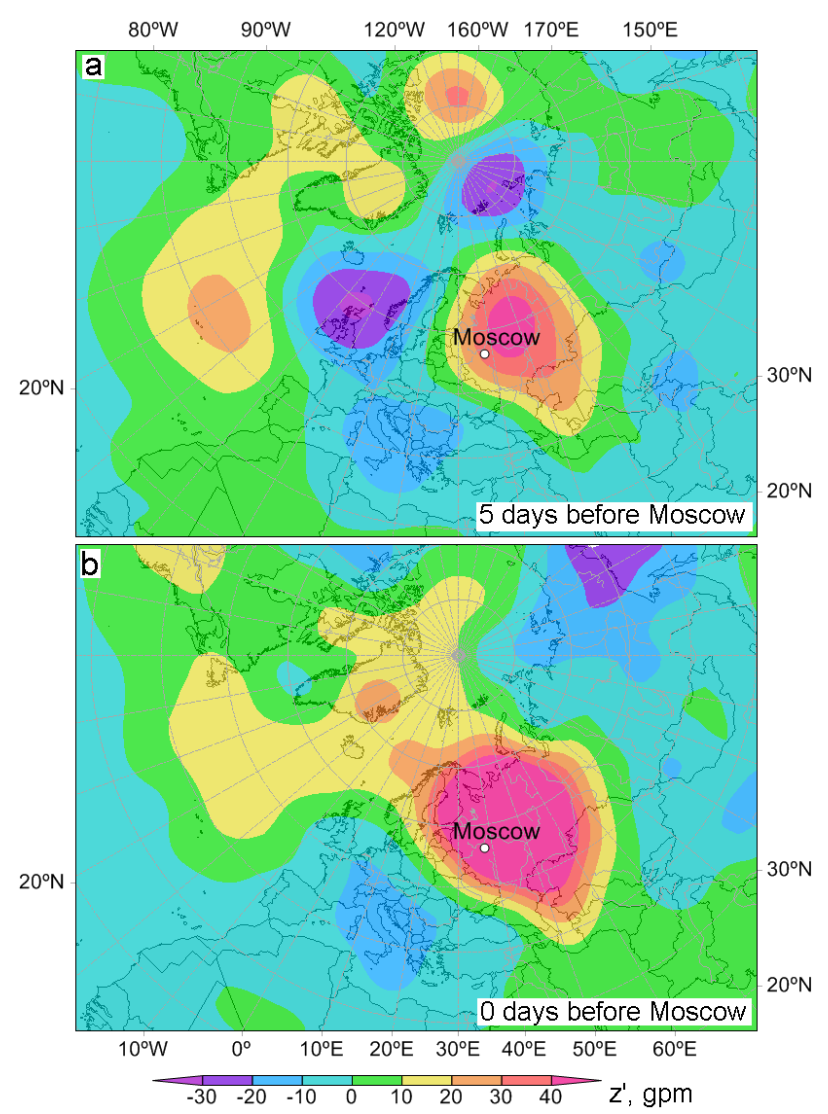

Fig. 5. The geopotential height for composite of dates 5 days before arrival (a) and for composite of days of arrival (b) of air parcels from the Aral Region to Moscow.
In this paper, we also analyzed the fields of geopotential height for composite of dates 5 days prior to arrival and for composite of days of arrival of air masses with a high aerosol content of fraction A2 from the Aral Region to Moscow (Fig. 5). It is seen that, as in [21], the transport from the Aral Region also occurs against the background of an extensive anticyclonic anomaly of the geopotential height with the center above the middle Urals. This anomaly existed on average $>5$ days before the day of arrival, i.e. there was a blocking anticyclone. As can be seen from Fig. 5 during the transport from the Aral Region, this anomaly increased and expanded.

\section{Conclusions}

It was found that the Aral Region and Northern Africa make the largest average contribution to the volume concentration of the aerosols with particle sizes in the range 1.0-5.0 $\mu \mathrm{m}$ (fraction $\mathrm{A} 2+\mathrm{A} 3$ ) in the atmosphere over Moscow. Extreme volume concentrations of the $\mathrm{A} 2+\mathrm{A} 3$ fraction in the troposphere of Moscow are associated with the air masses transport from Aral Region along the southwestern periphery of a blocking anticyclone centered over the southern Urals. With a high probability, the aerosols of fraction A2+A3 from the Aral Region are partially or completely composed of silicates.

We are grateful to the Moscow AERONET station's stuff and personally to Head of this station Natalia Chubarova.

\section{References}

1. P. Micklin. Annu. Rev. Earth Planet. Sci., 35, 47 (2007)

2. R.M. Razakov, K.A. Kosnazarov, The Aral Sea Basin, (Springer, Berlin, Heidelberg 1996)

3. G.I. Gorchakov, B.M. Koprov, K.A. Shukurov, Izv. Atmos. Ocean. Phys., 38 (1), S138 (2002)

4. G.I. Gorchakov, B.M. Koprov, K.A. Shukurov, Izv. Atmos. Ocean. Phys., 39(5), 536 (2003)

5. G.I. Gorchakov, B.M. Koprov, K.A. Shukurov, Izv. Atmos. Ocean. Phys., 40(1), 679 (2004)

6. Khrgian A.K., Physics of the Atmosphere (Leningrad, Gidrometeoizdat, 1969) [in Russian]

7. K.A. Shukurov, L.M. Shukurova, Izv. Atmos. Ocean. Phys., 53(3), 316 (2017)

8. B. Holben, T. Eck, I. Slutsker et al., Remote Sens. Environ., 66, 1 (1998)

9. N.Y. Chubarova, A.A. Pollukhov, and I.D. Gordova, Atmos. Meas. Tech., 9, P. 313 (2016)

10. O. Dubovik, T. Lapyonok, Y. Kaufman et al., Atmos. Chem. Phys., 8, 209 (2008)

11. R.R. Draxler, G.D. Hess, Aust. Meteorol. Mag., 47, 295 (1998)
12. R.R.

Draxler,

G.D.

Hess, http://ready.arl.noaa.gov/HYSPLIT.php (2014)

13. E. Kalnay, M. Kanamitsu, P. Kistler et al., Bull. Am. Meteorol. Soc., 77, 437 (1996)

14. R. Kistler, E. Kalnay, W. Collins et al., Bull. Am. Met. Soc., 82(2), 247 (2011)

15. J.E. Penner, M. Andreae, H. Annegarn et al., Intergovernmental Panel on Climate Change, Report to IPCC from the Scientific Assessment Working Group (WGI) (Cambridge University Press, 2001)

16. K. A. Shukurov, L. M. Shukurova, Proc. SPIE 10466, 104663W (2017)

17. Y.-K. Hsu, T. Holsen, O. Hopke, Atmos. Environ., 37, 545 (2003)

18. Y.Q. Wang, Meteorol. Appl. 21, 360 (2014)

19. R. Stull, An introduction to boundary layer meteorology (Dordrecht/Boston/London: Kluwer Academic, 1988)

20. G.I. Gorchakov, P.O. Shishkov, V.M. Kopeikin et al., Atmos. Ocean. Opt., 11(10), 958 (1998)

21. K. A. Shukurov, L. M. Shukurova, Proc. SPIE 10466, 104663U (2017) 